\title{
MINI COLETÂNEA DE CONTOS PIONEIROS DA LITERATURA INFANTIL HEBRAICA
}

\section{MINI COLLECTION OF PIONEERING STORIES FROM HEBREW CHILDREN'S LITERATURE}

Gabriel Steinberg*

\begin{abstract}
Resumo: Apresenta-se aqui uma minicoletânea de contos destinados ao público infantil, do período do renascimento do hebraico vernacular na Europa e na Terra de Israel, nas últimas décadas do século XIX e primeiras décadas do século XX. São apresentados aqui três contos de Itzhak Berkman (1870 - 1940) e dois contos de Meir Dizengoff (1861 - 1936). Itzhak Berkman foi um escritor e educador hebreu nascido na Lituânia e que viveu também nas cidades de Lodz e Varsóvia, na Polônia. Já Meir Dizengoff nascido na Bessarábia, foi um importante ativista sionista. Tornou-se mais conhecido por ter sido o primeiro prefeito da cidade de Tel Aviv, entre 1911 e 1936.
\end{abstract}

Palavras-chave: Literatura judaica. Literatura infantil hebraica. Língua Hebraica.

\begin{abstract}
This text presents a mini collection of short stories aimed at children, from the period of the revival of vernacular Hebrew in Europe and in the Land of Israel, in the last decades of the 19th century and the first decades of the 20th century. Here are presented three short stories by Itzhak Berkman (1870 - 1940) and two short stories by Meir Dizengoff (1861 - 1936). Itzhak Berkman was a Lithuanian-born Hebrew writer and educator who also lived in the cities of Lodz and Warsaw, Poland. Meir Dizengoff, born in Bessarabia, was a leading Zionist activist. Is best known for being the first mayor of the city of
\end{abstract} Tel Aviv, between 1911 and 1936.

Keywords: Jewish Literature. Hebrew children's literature. Hebrew language.

Shnei haachim (Os Dois Irmãos) / Itzhak Berkman - publicado em Varsóvia em 1910

Há muito tempo, viviam dois irmãos pequenos e órfãos. Eles sempre passavam frio e fome, mas se amavam muito e todo pedaço de pão que conseguiam, dividiam entre si em partes

\footnotetext{
* Gabriel Steinberg é professor no Departamento de Letras Orientais da Faculdade de Filosofia, Letras e Ciências Humanas da Universidade de São Paulo.

E-mail: <steinberg1818@usp.br>.
} 
iguais. Uma vez os dois estavam caminhando, o dia todo não haviam comido nada, e eis que diante deles apareceu um pastor com seu rebanho. Então eles se dirigiram ao homem e lhe disseram:

- Bom pastor, dê-nos um pouco de seu pão - imploraram os órfãos.

E o pastor lhes disse: Esta é minha última fatia de pão, podem ficar com ela, comam à vontade! - disse o pastor e entregou-lhes o resto do pão.

Quando os órfãos receberam o pão, o irmão mais velho deu ao jovem toda a fatia, ao que o mais novo retrucou e disse:

- Não, meu irmão! Eu me apoiei em você ao longo de toda a estrada, você está muito mais cansado do que eu, vamos dividir o pão entre nós - disse o pequeno.

E os irmãos tomaram o pão e o dividiram entre eles, então eles comeram-no e ficaram aliviados da fome. Depois de comer, eles continuaram andando até que chegaram a uma encruzilhada. Ali havia uma placa pendurada na qual puderam ler o seguinte: "Aquele que seguir pela direita haverá de ser um rei, e aquele que seguir pela esquerda, será um homem rico". Quando acabaram de ler essas palavras, o irmão mais novo disse ao mais velho:

- Vai você, meu irmão pela direita, já que você é mais inteligente e possuidor de sabedoria, nada mais justo que se torne um rei.

E assim os irmãos se separaram e seguiram caminhos diferentes, o primogênito foi para a direita e o mais novo seguiu pela esquerda. Por muito tempo andou o irmão mais velho, até que chegou a uma terra distante. Ele entrou na casa de uma velha e pediu-lhe um lugar para dormir. Ao amanhecer levantou-se, vestiu-se, lavou o rosto e orou.

Nesse reino, o rei tinha morrido naquela época, não deixando nenhum herdeiro, exceto uma filha. Por isso, todo o povo do reino se reuniu na sinagoga. Cada homem compareceu com uma vela na mão, estabelecendo em conjunto a seguinte condição: aquele homem cuja vela se acender por si mesma em primeiro lugar será o rei e, ainda, se casará com a linda princesa. Sabendo disso, a velha apressou-se e entregou uma vela às mãos do jovem hospede e lhe disse:

- Pegue esta vela, meu filho, e vá correndo para a sinagoga - disse ao rapaz - quem sabe esta vela se acendará primeiro.

Levantou-se o órfão e dirigiu-se à sinagoga. No caminho ele viu um cego perdido, e, no entanto, ninguém o acudiu porque todos estavam com pressa para chegar à sinagoga. Somente o jovem se compadeceu do cego. Ele deixou de lado o plano de escolha do novo rei e não abandonou o cego até que o conduzisse à casa de caridade da cidade. Somente então o jovem correu até a sinagoga, e assim que adentrou no recinto, sua vela se acendeu. $\mathrm{O}$ órfão ficou pasmo com a visão, ele virou-se para um lado e para outro, e nesse instante ele viu uma 
inscrição brotando no ar na qual podia ler: "Você foi uma luz para um cego e por isso, sua vela brilhará!".

As pessoas da cidade ficaram com inveja do jovem e começaram a assoprar sua vela para apagá-la. Mas, nesse instante, a filha do rei viu o que estava acontecendo e por isso apressou-se, ergueu seu cetro de ouro e exclamou:

- Não ousem tocar nele, pois sua vela se acendeu primeiro. Sendo assim, é ele o herdeiro ao trono.

E assim que a filha do rei concluiu suas palavras, o povo acorreu até o órfão e imediatamente o conduziram até a jovem princesa. Ela lhe deu seu anel de ouro e o convidou para morar no palácio. Quando ele cresceu e se tornou sábio e muito culto, eles se casaram. Ele se tornou um rei bom, misericordioso com os mais pobres, amante da justiça e da lealdade, e seu irmão tornou-se seu conselheiro.

\section{Hamichtav (A Carta) / Itzhak Berkman - publicado em Varsóvia em 1910}

Shmuel era um bom menino, porém bastante disperso. Quando ele fazia algo errado, sua mente sempre o repreendia. E aconteceu diversas vezes que ele sequer prestava atenção ao que sua própria boca dizia. Certa vez, ele enviou uma carta à sua avó que morava numa cidade distante. A carta em si era muito bonita, pois nela ele escrevera sobre a vida no vilarejo no qual seus ancestrais sempre tinham vivido, sobre os estudos, e como era que ele passava o seu tempo livre. Quando concluiu a carta, dobrou a folha com o intuito de inseri-la no envelope, mas aconteceu que, sem perceber, ele acabou inserindo no envelope uma folha em branco, deixando a carta esquecida entre as páginas de um livro.

A carta em branco de Shmuel chegou à cidade onde morava sua avó, depois de muitas andanças por estradas distantes, permanecendo na sacola do carteiro, entre outras cartas, telegramas, convites e algumas notas promissórias. Nesse instante, as cartas começaram a tagarelar entre si: - Para onde você está sendo levada? - perguntou a folha em branco à sua vizinha, uma carta com linda caligrafia que se encontrava dentro de um envelope caro. - $\mathrm{O}$ endereço no envelope é uma prova clara de que estou destinada a uma família destacada respondeu a carta com orgulho - e lamento muito por estar aqui no meio de todas estas cartas sujas, enfiadas dentro de envelopes simples e rústicos. 
Ao ouvir essas palavras, uma outra carta lhe respondeu: - Você consegue perceber que aqui, do lado esquerdo, aparece a assinatura de um soldado? E o papel? Se você visse a simplicidade do papel, e as letras tortas? Elas parecem estacas, mas que culpa tenho eu continuou a carta do soldado se lamentando - se me colocaram aqui no mesmo lugar que você, uma carta tão distinta, não foi por minha vontade que fui colocada aqui ao seu lado. Mas saiba você que o envelope no qual você se encontra é realmente refinado, e a folha de papel é lisa e brilhante, porém o conteúdo..., quantas mentiras, bajulação e futilidades! - Perversa - disse a distinta carta - seu atrevimento e ousadia são prova de quem você é realmente...

Mas nesse instante o carteiro tomou a orgulhosa carta e a entregou ao porteiro de um templo - Que o nome do Senhor seja abençoado - brincou a carta do soldado - agora ficamos um pouco mais aliviados, um arrogante a menos. Se o tolo soubesse o que está escrito em mim - disse a carta do soldado. - E o que está escrito em você? - perguntou a folha em branco de Shmuel. Ao que o envelope sujo e rústico respondeu: - eu fui escrita por um soldado submetido a trabalhos forçados num acampamento, há quatro anos que o soldado está trabalhando duramente, e durante todo esse período ele não pôde ver sua amada mãe. Na carta ele narra seu sofrimento ao longo de todo esse período, mas também lhe anuncia que, muito em breve, em no máximo um mês, eles voltarão a se encontrar, o soldado com sua idosa e solitária mãe.

Foi assim que as cartas conversaram por algumas horas, enquanto o carteiro corria de casa em casa entregando as missivas, até que chegou a vez da carta de Shmuel. Nesse instante, o carteiro entregou a carta ao porteiro que a entregou à ajudante e essa à mãe, e a mãe à avó, que nessa hora encontrava-se sentada tricotando ao lado da janela. A velha pôs os óculos sobre o nariz, abriu o envelope com muito cuidado e tirou dele a "carta"! A vovó cuspiu três vezes e depois disse:

- Quem foi o tolo que teve coragem de fazer esta brincadeira? Até o dia primeiro de abril ainda falta mais de um mês...

HaQossêmet (A mágica) / Itzhak Berkman - publicado em Varsóvia, 1910

Numa terra distante, além do mar, vivia uma viúva. Ela tinha uma filha chamada Hannah e uma enteada chamada Shoshana. A viúva amava sua filha com um forte amor, porém detestava a enteada. Hannah não tinha uma boa aparência e era maliciosa, ao passo que Shoshana destacava-se pela beleza, pela bondade e até pela generosidade. A madrasta impunha todo o trabalho da casa e do quintal apenas sobre Shoshana. Ela devia esfregar todos os pisos 
da casa, caminhar longe para trazer água do poço, e mesmo assim, a madrasta não se contentava com o árduo trabalho imposto e não perdia a oportunidade de atormentá-la, insultá-la e, até, infligir-lhe, com certa frequência, algumas surras. Enquanto isso, Hannah passava os dias e as noites deitada em sua cama, comia e se embelezava, e sua mãe sempre a elogiava e a cobria de afeto e, ainda, a elogiava dizendo que ela era linda e inteligente, demonstrando orgulho infinito de sua filha Hannah.

Certa vez, Shoshana foi tirar água do poço que ficava a alguns quilômetros da cidade, carregando em suas mãos um enorme jarro. Assim que se aproximou do poço, apareceu uma pobre anciã, ela era maga. A velha então lhe disse:

- Por favor, me dê um pouco de água do seu jarro, linda garota.

Então Shoshana lhe respondeu: - Beba, senhora, beba, minha querida! - disse Shoshana demonstrando toda a bondade que invadia seu coração, enquanto apoiava o jarro na palma da sua mão, abaixando-o para que a velha pudesse beber. Quando a anciã acabou de beber disse:

- Obrigada linda garota! Eu vejo que você tem um bondoso coração e por isso você será recompensada, cada vez que uma palavra sair de sua boca ela virá acompanhada por uma flor bem perfumada ou por uma pedra preciosa.

E assim que a velha acabou de falar, imediatamente desapareceu. Quando Shoshana voltou do poço, ela foi humilhada pela madrasta que lhe disse:

- Menina travessa! Por que demorou tanto tempo para voltar?

- Me perdoe por ter demorado mais tempo do que de costume - respondeu Shoshana brevemente.

- Mas, o que é isto? Ó meu Pai que estás nos céus! Que maravilha! - gritou a madrasta e, rejubilando-se, prostrou-se ao chão para coletar as rosas e as pedras preciosas que se desprendiam da boca de Shoshana.

Enquanto a enteada contava para a viúva tudo o que lhe tinha acontecido perto do poço, cada palavra que ela soltava tornava-se uma pedra preciosa ou uma flor. Então a viúva foi ofegante chamar Hannah, e lhe disse:

- Acorda minha querida, corre até o poço e traz água para mim, mas rápido, se apresse minha filha.

- Era só isso que me faltava - respondeu Hannah - Eu nunca tirei água do poço e não será desta vez que haverei de perder a razão e irei até esse lugar distante - respondeu irritada à sua mãe enquanto se revirava na cama de um lado a outro. 
Com muito esforço, a viúva conseguiu colocar Hannah de pé, deu-lhe um lindo e pequeno recipiente e enviou-a ao poço. A idosa mágica que já estava esperando por ela no poço, aproximou-se de Hannah e pediu-lhe um pouco de água. - Eu não sou sua serva respondeu Hannah irritada - eu tirei a água para mim, saia logo daqui!

Então a velha lhe disse: Por causa do teu bondoso coração eu te darei um presente, e assim, cada palavra que sair de sua boca se transformará num sapo ou numa cobra que se desprenderão dos teus lábios. Hannah franziu o cenho, e no caminho para casa, tomada pela ira, quebrou o recipiente.

- Por que você voltou com tanta pressa? - perguntou a viúva à filha.

- Saia daqui, já estou cansada de você e de suas perguntas - respondeu Hannah com uma voz tão irada, que ela mesma assustou-se com tais palavras. Porém, seu susto ficou maior ao perceber que cada palavra que saía de sua boca tornava-se um sapo verde e asqueroso ou uma serpente rastejante.

- Eu sei quem é a culpada por tudo isso, - gritou a viúva com uma voz terrível enquanto atacava Shoshana, sua enteada com seus punhos. A pobrezinha fugiu dali humilhada e ferida, e se escondeu muito longe, entre as montanhas.

Naquele dia o jovem filho do rei saiu para caçar na floresta. Perto daquele lugar vivia um bom mago. O filho do rei numa outra ocasião havia pedido ajuda a ele para achar uma bela e delicada noiva. Foi então que o mago apareceu diante dele e aconselhou-o a casar com a bela Shoshana. Então o filho do rei saiu à procura dela, encontrando-a entre as montanhas. Quando a achou, o príncipe lhe perguntou:

- O que você está fazendo aqui, bela moça? - Enquanto ele falava com Shoshana, percebeu que seus olhos estavam marejados de lágrimas.

- Eu fugi de minha madrasta - respondeu a órfã em prantos, e cada palavra que saia de sua boca tornava-se um lírio ou uma pedra preciosa. - O filho do rei, extasiado com sua beleza, disse:

- Esta menina é um verdadeiro tesouro! - Então ele tomou Shoshana por esposa, expulsando a madrasta e sua perversa filha do reino.

Shnei rehim (Dois amigos) / Meir Dizengoff - conto publicado em 1893

Shalom era um dos meus amigos a quem eu amava muito. Já tinham se passado cerca de três anos desde que começáramos a nos sentar um ao lado do outro na escola. De manhã 
saíamos juntos de nossas casas para ir à escola, pois nós éramos vizinhos e até nossas casas eram próximas. Assim que acabavam as aulas, eu costumava ir até a casa do meu amigo, ou ele vinha até minha casa, e muitas vezes costumávamos comer um na casa do outro. E assim, desde pequenos, nos acostumamos, Shalom e eu, a estar juntos na escola, em casa até na rua.

Aconteceu uma vez que, num dia de verão à noite estávamos andando à beira-mar recolhendo pequenas conchas. Estava muito quente, então eu disse ao meu amigo Shalom:

- Vamos entrar no mar para refrescar-nos na água, mas que ninguém fique sabendo (porque nossas mães nos proibiram de tomar banho no mar sem estar na companhia de um professor ou dos nossos pais).

Shalom ficou feliz com a ideia, então começamos a tirar nossas roupas com pressa, pois desejávamos correr para a água e nadar o quanto pudéssemos, já que não havia ali ninguém que pudesse nos deter.

Quando voltamos da água, Shalom começou a sacudir suas roupas a fim de tirar toda a areia que tinha se grudado nelas, e seus pés estavam separados, um na areia, outro na água, pois ele desejava lavá-los antes de vestir as calças. E aconteceu que, quando ele levantou a perna direita para colocar as calças, perdeu o equilíbrio, caiu na água e todas suas roupas ficaram molhadas, o seu relógio caiu no mar e nunca mais foi visto.

Por cerca de duas horas procuramos o relógio em todas as margens do mar, cavamos muitos buracos em toda a areia à nossa frente, mas foi tudo em vão, pois não conseguimos encontrar o relógio. Sentimos muito pela perda de um objeto tão valioso, porém, e mais do que isso, temíamos a repreensão de nossos pais, pois nós havíamos os desobedecido suas ordens entrando na água do mar para nos banharmos quando ninguém estava conosco. Conhecendo Shalom como eu o conhecia e por ele ter seguido meu conselho de entrarmos na água mesmo sem um adulto por perto, minha alma ficou apreensiva.

Aconteceu que, vendo meu amigo, irado porém triste, repentinamente lhe disse:

- Escute o que tenho para te dizer: pega meu relógio e retorna à casa de teu pai, e não diga nada a ninguém. Meu relógio é idêntico ao teu, porque nossos pais os compraram juntos para nós, e eu me esforçarei para que meu pai não perceba que o relógio não está comigo, assim, alguns dias se passarão e então veremos o que fazer.

Assim se passaram cerca de seis meses sem que ninguém soubesse o que tinha nos acontecido, e sem que meu pai percebesse a ausência do relógio. Mas um dia, meu pai decidiu viajar a Jerusalém, porém ele não sabia se a hora marcada em seu relógio estava certa, e temia perder a partida da locomotiva que seguiria da cidade rumo a seu destino. Então ele me 
perguntou as horas com o intuito de acertar seu relógio. Ao ouvir a pergunta do meu pai, meu rosto estremeceu e meus olhos se encheram de lágrimas. Foi então que contei a ele tudo o que havia acontecido conosco, comigo e com Shalom, meu amigo. Meu pai não me disse nada naquele dia, porque estava com pressa para partir.

Aconteceu que, quando voltou de Jerusalém, ele me trouxe um novo relógio, igual ao que eu tinha dado a Shalom. Então eu fui correndo e contei tudo à minha mãe, e ambos me beijaram muitas vezes. Nesse dia fiquei muito feliz.

Mechaiei Yshai, hateymani (A vida de Yshai, o iemenita) / Meir Dizengoff - conto publicado em 1934

Vocês conhecem Yishai, o iemenita?

Ele é um menino de baixa estatura, seus olhos e cabelos são negros como os de um corvo, ele é alegre, ágil e cheio de vida. Yshai tem apenas dezoito meses de vida, mas seu caráter e determinação já são bem perceptíveis. Ele não fica preso atrás dos movimentos de mãe na cozinha, como fazem as crianças de sua idade, mas se sente atraído para a sala de estar. Yshai aproxima-se de todo convidado que vêm visitar a família, sussurra-lhe algumas palavras na sua língua incompreensível, como se estivesse se apresentando e perguntando pelo bemestar da visita.

Depois de estabelecer laços de amizade com todos os convidados, ele se vira e se aproxima de mim, do "tio", levanta as mãos na vontade de sentar-se sobre meus joelhos. A conversa entre nós não dura muito tempo, pois nos entendemos por dicas e olhares, e então também cantamos juntos uma das canções mais conhecidas entre nós: "Se eu não for por mim, quem será?", ou "Nós viemos a esta terra para construí-la e para sermos nela reconstruídos".

Às vezes e de repente, Yishai corre e se apressa para pegar o telefone, e quando ele coloca o fone no ouvido, começa a chamar tal como fazem os adultos: "Alô, alô, quem está falando?" esperando uma resposta. E quando percebe que não há uma resposta, ele devolve o aparelho ao lugar com visível decepção e se aproxima da minha estátua que está de pé num dos cantos da sala. No início, Yshai teve muito medo desta estátua de granito preto, e somente depois que sua mãe lhe explicou que aquele da escultura era o "tio", ele começou a abraçar e a beijar a cabeça ereta e imóvel e a sussurrar: "Tio, tio". Imediatamente depois disso, ele corria até o grande espelho que se encontrava pendurado na parede e olhava para ele por um longo tempo. Em sua pequena mente, duas impressões aparentemente surgiam, uma em oposição à 
outra: a estátua imóvel ao lado do "tio" vivo, e sua imagem no espelho ao lado de um ser pequeno e vivaz.

Yshai é, por natureza, um garoto pequeno, mas esperto e atento que entende as coisas à sua volta e responde a tudo o que acontece ao seu redor com vigor e sem demora. Ao ouvir, por exemplo, a sirene do carro de bombeiros ele fica muito excitado e começa a correr daqui para lá resmungando algumas palavras incompreensíveis, como se quisesse dizer: "O que vocês estão esperando? Não percebem que lá está acontecendo algum desastre?". Quando é levado para um passeio na praia, ele é atraído pelas ondas brancas que requebram sobre a costa, e somente com grande esforço conseguem trocar-lhe as roupas que se molharam com o estourar das ondas. E como ele fica feliz quando o vestem com sua roupa de banho e o deixam sentado dentro da água do mar. Ele se deleita brincando com as ondas e se recusa a deixar o mar por muitas horas.

Yishai é também dotado de uma incrível memória. Uma vez ele colocou a mão no fogão aceso se queimando de leve. Sua mãe então lhe disse: "Está quente, não toque!". Daquele momento em diante, a palavra "quente" ficou gravada em sua memória como sinônimo para toda dor e todo problema. E até quando os pernilongos o picavam ou a areia entrava em seus olhos, Yishai exclamava: "Quente, quente!".

Yshai odiava qualquer truque ou injustiça. Uma vez o levei para um passeio de carro. Ele gostou tanto do passeio, que quando a viagem acabou e tentaram tirá-lo do carro, protestou com todas as forças contra essa injustiça, gritou e chorou tanto que não foi possível consolálo. Essa mesma situação se repetiu também uma vez enquanto ele estava sendo retirado do carro que eu dirigia até o porto para embarcar em um navio que me levaria ao exterior. No início, quando o sentaram no carro, ele foi tomado por uma grande alegria. Sentou-se ao lado do motorista e imediatamente aprendeu a buzinar, até tentou girar o volante. Mas quando eu e meu acompanhante subimos no carro, e Yshai foi retirado dali e entregue aos braços de sua mãe, ele começou a gritar e a sacudir as mãos e os pés sem parar, como se quisesse dizer: "Achei que todos nós iriamos viajar, e agora vocês viajam e me deixam aqui!".

Yishai adora cantar e dançar. Ele sempre pede à Lulu, sua babá, para que ela cante músicas e ele possa dançar. Em geral, ele gosta de cantar músicas que ouviu de crianças no jardim de infância ou na casa de seus pais. Quando ele comete um erro na música, ou quando revira alguma coisa na sala, ele pede "Icha" ("desculpe" na língua dele). Uma vez Yishai encontrou na sala de estar um dos delegados do exterior que veio me visitar. As roupas elegantes e o bastão com o cano prateado o impressionaram de tal forma, que Yshai concluiu 
que aquele homem tinha vindo para algum casamento. Então ele tomou para si aquele bastão de sua mão e o convidou para dançar "Yulla".

Como já disse anteriormente, Yshai é grande amante da vida e da alegria e, acima de tudo, adora ir e dançar nos casamentos dos iemenitas. É muito difícil resistir à sua vontade, porque senão, ele grita, protesta e chora e faz uma algazarra. Ele não é nem covarde e nem tímido. Enquanto caminha pelo Boulevard Rothschild, se aproxima de um grupo de pessoas como se quisesse participar de suas conversas. E se ele não for notado por um grupo, ele muda e se aproxima de algum outro grupo.

Em geral, Yishai, o iemenita, ganhou grande notoriedade mesmo tendo poucos meses de vida. Todos o conhecem e o reconhecem, e ele mesmo ama as pessoas e busca uma forma de se fazer notar. Se vocês ainda não sabiam nada até agora a seu respeito, eis que esta historinha veio para torná-lo um pouco mais conhecido.

\section{Referências bibliográficas}

BERKMAN, Itzchak - Shnei haachim (Os dois irmãos) Project Ben Yehuda. Disponível em: <https://benyehuda.org/read/13946>, acesso em 16/11/2020.

BERKMAN, Itzchak -Hamichtav (A carta) Project Ben Yehuda. Disponível em: <https://benyehuda.org/read/13947>, acesso em 16/11/2020.

BERKMAN, Itzchak - Hakossemet (A mágica) Project Ben Yehuda. Disponível em: <https://benyehuda.org/read/13948>, acesso em 16/11/2020.

DIZENGOFF, Meir - Shnei rehim (Dois amigos) Project Ben Yehuda. Disponível em: $<$ https://benyehuda.org/read/5825>, acesso em 26/11/2020.

DIZENGOFF, Meir - Mechaiei Yshai, hateymani (A vida de Yshai, o iemenita) Project Ben Yehuda. Disponível em: <https://benyehuda.org/read/6472>, acesso em 26/11/2020. 